\title{
A shared care system of hospital follow up reduced pain and use of healthcare resources and increased satisfaction in patients with rheumatoid arthritis
}

\author{
Hewlett S, Mitchell K, Haynes J, et al. Patient-initiated hospital follow-up for rheumatoid arthritis. Rheumatology 2000 \\ Sep;39:990-7.
}

QUESTION: Is a patient and general practitioner initiated shared care system more effective than traditional rheumatologist initiated hospital care in patients with established rheumatoid arthritis?

\section{Design}

Randomised \{allocation concealed\}*, unblinded, controlled trial with 2 years of follow up.

\section{Setting}

A rheumatology outpatient department in Bristol, UK.

\section{Patients}

209 patients who had established rheumatoid arthritis (mean disease duration 11.5 y). 182 patients $(87 \%)$ (mean age 58 y, 68\% women) had complete follow up.

\section{Intervention}

105 patients were allocated to a shared care system of no routine hospital follow up but with rapid access to multidisciplinary team review on request by patients or general practitioners (GPs) (shared care group). The patients or GPs requested review by any team member through a telephone helpline staffed by a nurse who also gave general advice or assistance. The maximum wait for review was 10 working days. 104 patients were allocated to traditional rheumatologist initiated hospital care with planned reviews every 3-4 months (traditional care group). These patients had access to the occupational therapist (OT) and physiotherapist (PT) through the traditional route of GP request, rheumatologist appointment, and waiting lists to see the OT or PT.

\section{Main outcome measures}

Clinical and psychological status, use of healthcare resources, patient satisfaction with care and confidence in the system, and safety net failure (defined as an increase of $\geqslant 20 \%$ in pain, disease activity, or disability).

\section{Main results}

Patients in the shared care group had less pain than those in the traditional care group $(3.9 v 4.8 \mathrm{~cm}$ on a $10 \mathrm{~cm}$ visual analogue scale, $\mathrm{p}<0.05$ ), a smaller increase in pain over 2 years $(0.4 v 1.6 \mathrm{~cm}, \mathrm{p}<0.01)$, and greater self efficacy for function $(\mathrm{p}<0.05)$; used less resources $(£ 208 v$ $£ 313 /$ patient $/ y, p<0.001)$; and had greater satisfaction with care $(\mathrm{p}<0.05)$ and confidence in the system $(p<0.05)$. No differences existed between groups for changes in patient opinion of disease activity, disability, changes in psychological status, or safety net failure.

\section{Conclusion}

A patient and general practitioner initiated system of hospital follow up reduced pain and use of healthcare resources, and increased patient satisfaction and confidence with care in patients with rheumatoid arthritis.

*Information provided by author.

\section{COMMENTARY}

Patients with rheumatoid arthritis are typically monitored by hospital rheumatologists using a costly predefined follow up schedule with the goal of reducing long term disability. ${ }^{2} \mathrm{~A}$ problem with a predetermined follow up schedule is that patients may be seen at times when they do not require help and may not be able to easily and rapidly access the system in times of need. The study by Hewlett $e$ t al, unlike others, evaluates a more flexible system of review where patients or their GPs self initiate rapid access to specialist advice as needed while, at the same time, reducing unnecessary follow up appointments.

The mean duration of disease in the patients in this study was 11.5 years. Many patients reviewed in hospital will have much shorter disease duration and still be closely monitored during the early stages of second line treatment. This study does not clearly suggest the time point at which patient and GP initiated hospital follow up should be recommended. Only $69 \%$ of patients agreed to participate in the study. With respect to generalisability of findings, it is important for readers to keep in mind that patients who refused to participate were older, had a higher mean articular index, and were more disabled. The authors suggest that shared care may need to be targeted at certain patient groups. Hewlett $e t$ al included safety net monitoring, which was not costed. Safety net monitoring would need to be incorporated if a patient initiated system were to be established, and any arising problems, including extra-articular manifestations, would need to be recognised at an early stage. Patient costs were not included; only health services resource costs were considered.

This study is of particular interest to both hospital and primary care nurses who care for patients with inflammatory joint disease. Although patient satisfaction and confidence were increased with empowerment, further research is needed on the economics, long term outcome, and educational needs of staff.

Elizabeth M Barrett, RGN, MSc, RHV Clinical Manager, ARC Norfolk Arthritis Register St Michael's Hospital Aylsham, Norfolk, UK

1 Scott DL, Shipley M, Dawson A, et al. The clinical management of rheumatoid arthritis and osteoarthritis: strategies for improving clinical effectiveness. Br J Rheumatol 1998;37:546-54.

2 Cooper NJ, Mugford M, Scott DG, et al. Secondary health service care and second line drug costs of early inflammatory polyarthritis in Norfolk, UK. J Rheumatol 2000;27:2115-22. 